\title{
BANACH SPACES OF FUNCTIONS TAKING VALUES IN A $C^{*}$-ALGEBRA
}

\author{
Orapin WootiJirutTikal, S.-C. Ong, P. Chaisuriya AND J. RAKbUd
}

Abstract. Let $\mathscr{A}$ be a $C^{*}$-algebra with identity 1 ; and let $s(\mathscr{A})$ denote the set of all states on $\mathscr{A}$. The state space $s(\mathscr{A})$ (with the weak* topology) is used to construct classes of Banach spaces of functions defined on a fixed set $S$ taking values in $\mathscr{A}$. The inter-relationship between spaces are considered. Special classes of operators on these spaces are also considered. When $\mathscr{A}$ is taken to be $\mathbb{C}$ and $S$ to be $\mathbb{N}$, all spaces are just the classical spaces.

Mathematics subject classification (2000): Primary 46B25, 46B45; Secondary 47B38.

Keywords and phrases: Banach space, $C^{*}$-algebra, state space.

\section{REFERENCES}

[1] P. Chaisuriya, S.-C. Ong, And S. Wang, Schur Algebras over $C^{*}-$ Algebras, Intl J. Math. \& Math. Sci. ID 63808 (2007), 15 pp.

[2] J. DiXMIER, Les fonctionnelles linéaries sur l'ensemble des opérateurs bornés dans espace de Hilbert, Ann. Math., 51 (1950), 378-408.

[3] N. Dunford, J. T. Schwartz, Linear Operators, Part I, Interscience Publishers, Inc., New York, 1957.

[4] R. V. Kadison and J. R. Ringrose, Fundamentals of the Theory of Operator Algebras, Academic Press, New York, vol. I, 1983.

[5] R. Schatten, Norm Ideals of Completely Continuous Operators, Erg. d. Math. N. F. 27, SpringerVerlag, Berlin, 1960. 